\title{
18. Formatting Nostalgia
}

\author{
IMAX Expansions of the Star Wars Franchise
}

\author{
Allison Whitney
}

On July 8, 2014, J.J. Abrams's production company, Bad Robot, released a tweet with an image of an IMAX camera suspended over a desert landscape, with the hashtag \#bestformatever. ${ }^{1}$ At this point in time, the company had released only a few oblique details about the production of The Force Awakens; while it was not immediately clear if they were shooting the film in this format, the image inspired speculation about how the much-anticipated Star Wars film might be enhanced by the experience of IMAX. However, this was not the first intersection of Star Wars and IMAX. In this essay, I will address how IMAX iterations of three Star Wars films draw upon viewers' transmedia experiences with and nostalgia for the franchise.

The 1996 documentary Special Effects: Anything Can Happen, directed by Star Wars sound designer Ben Burtt, features a recreation of the opening sequence of A New Hope in IMAX format. Using IMAX's unique discourse of science documentary and sensory immersion, the recreation offers viewers a simulation of the theatrical awe that is central to Star Wars's place in popular history. Six years later, Attack of the Clones was among the first films to be reformatted for IMAX exhibition using the DMR (digital remastering) process. The IMAX version invited and magnified comparisons among and debates about the relative merits of digital and analog formats. While many twenty-first-century films have engaged in such discourse, Star Wars's decades-long rhetoric of technological innovation and cinematic nostalgia made Attack of the Clones's use of IMAX particularly interesting. Finally, The Force Awakens includes a sequence shot with IMAX cameras, a fact that played a key role in the film's promotional rhetoric by emphasizing its faithfulness to pre-digital filmmaking practices. These three applications of IMAX technologies offer illuminating case studies for how Star Wars's transmedia manifestations cultivate viewer sensitivity to the aesthetics and phenomenology of particular film formats and subsequently align those formats with nostalgic sentiment.

1 Bad Robot (@BadRobot), Twitter post, July 8, 2014, 2:51 p.m. https://twitter.com/bad_robot/ status/486628757780721664. 
Before I go any further, I must acknowledge the complexity of defining IMAX, a term that refers simultaneously to a corporate entity, several exhibition formats and systems, camera technology, and a film format. The founders of IMAX invented a 15/70 film system, which means 70mm film $(65 \mathrm{~mm}$ negative) with fifteen perforations per frame (standard $70 \mathrm{~mm}$ has five perforations). This is the largest film format in use, widely referred to as IMAX film. On the exhibition side, the IMAX brand covers several types of projection systems and theater designs. Historically, flat-screen IMAX involved screens between six and eight stories in height, with an aspect ratio of 1.43:1. These theatres are now referred to as IMAX GT (Grand Theater), the first permanent facility of which was built in 1971. 1973 saw the beginnings of IMAX Dome, also called OMNIMAX, where the image is projected into a dome and fills the audience's field of vision. A $3 \mathrm{D}^{\mathrm{D}}$ system was introduced in the mid-1980s. For the first 30 years of IMAX history, the majority of its cinemas were in museums, science centers, or at tourist sites, but, in the late 1990s, after a change in ownership, the company began to expand into other venues, introducing a smaller-screen design in 2003 termed MPX. In 2008, they debuted the $4 \mathrm{~K}$ IMAX Digital projector and, in 2015, they introduced IMAX Laser, a digital system that most closely approximates the look of $70 \mathrm{~mm}$ film. ${ }^{2}$

While each exhibition system creates distinct experiences, IMAX offers extreme sensory engagement, a rhetoric of immersive and participatory media, a feeling of "being in the picture," and a mode of cinema that is emphatically theatrical, in that it is impossible to recreate the geometry of IMAX in a home theater system. In this chapter, I discuss how these concepts inform each of the IMAX Star Wars films, encouraging viewers to consciously compare IMAX's properties to other formats, and to contemplate how format informs their engagements with the text. Furthermore, I consider how IMAX plays into the relationship between innovation and nostalgia, both in the films themselves and in their promotion and reception.

2 To complicate matters further, companies besides IMAX use 15/70 film and there are now competing digital projection systems that boast similarly large screens and high definition. Given that the films I discuss were produced in cooperation with the IMAX Corporation, it seems fair to use the term IMAX. Furthermore, there is now an IMAX digital camera, but it was not used for the titles I discuss here. 


\section{Special Effects}

Special Effects is a documentary that traces the history of cinematic illusions, explores the science behind effects' manipulation of perception, and features an homage to King Kong, as well as behind-the-scenes footage from the sets of Independence Day, Jumanji, Kazaam, and the 1997 original Star Wars trilogy special edition, including IMAX-format recreations of scenes from A New Hope. The special-edition production footage included scenes of stormtroopers on Tatooine, a visit to Lucasfilm to examine props and puppets from the original trilogy, and discussion of new innovations in digital effects that would appear in the forthcoming films. Special Effects not only cultivates interest in the special editions, but it also offers what we might regard as a series of historical reenactments. By demonstrating how they recreate the special effects for the IMAX version of A New Hope, the filmmakers essentially reenact the original film's production-they resurrect the physical objects, such as the spaceship models from the Lucasfilm archive, and the filmmaking techniques in order to rehearse the 1970s processes, all the while contemplating how IMAX cameras and digital tools offer new challenges and possibilities. The final product of these sequences is then shown to the audience, offering yet another kind of reenactment, as the experience of watching $A$ New Hope is reproduced in a theatrical setting.

On the surface, the opening space battle from A New Hope is a practical choice for IMAX recreation because it does not require actors or narrative set-up for unfamiliar viewers, but it also taps into popular narratives of spectatorship about this specific moment in the film. Indeed, many people who viewed A New Hope during its initial run describe the shot of the Star Destroyer flying overhead as transformative, not only for their engagement with the movie, but also for their understanding of cinema and its possibilities. For example, in "Zooming Out: The End of Offscreen Space," Scott Bukatman begins his essay with "You remember the shot [...] I'm sure you do," then goes on to describe the opening of A New Hope in the knowledge that any reader interested in an essay on special effects will recall how in that shot "new cinematic technologies redefined space, displaced narrative, and moved cinema into a revived realm of spectacular excess." ${ }^{3}$

When presented in IMAX, the scene's capacity to create visceral thrills and disorientation, while challenging traditional notions of perspective,

3 Scott Bukatman, "Zooming Out: The End of Offscreen Space," in The New American Cinema, ed. Jon Lewis (Durham: Duke University Press, 1998), 248. 
landscape, and mise-en-scène, calls upon viewers' memories of the text and of the material properties of the formats in which they have seen it. It allowed younger viewers who might only know Star Wars from VHS, but whose cinematic sensibilities had been shaped by the subsequent developments in special effects, to comprehend the awe of the original. At the same time, it allowed seasoned viewers to revisit the nostalgic pleasure of theatrical viewing, all the while positioning that experience within IMAX's unique discourse of sensory immersion. Special Effects thus attempted a simulation of the theatrical experience that is central to Star Wars's place in popular history.

In order to pull off this simulation, the filmmakers had to combine historical techniques with the newest technologies. Visual effects supervisor Bruce Nicholson "planned to film the original models and matte paintings with a motion controlled 15 perf $/ 65 \mathrm{~mm}$ camera, scan the original negative, and composite the elements digitally."4 Yet, as they worked on the project, they realized that the distinct features of IMAX film, specifically the frame's relationship to the viewer's field of vision and the high-definition image, complicated the illusion. First, the large size of the IMAX camera changed its spatial relationship to the models, so, instead of the five-foot-long Star Destroyer model from A New Hope, they had to use the eight-foot one from The Empire Strikes Back to create a comparable effect. ${ }^{5}$ Further, as the Star Destroyer flies overhead, Burtt allowed it to enter further into the frame than in the original film. In the IMAX facilities operating in the 199os, the frame would approach, or even extend beyond the audience's field of vision, and therefore Burtt realized that the object's relationship to the frame had to change accordingly. They also had to adapt the sound for the IMAX system; Nicholson notes that they took great pains to create "an exposure sheet timing the rhythm of the laserblasts" so that they would match the audience's memories of not only the sound effects but the precise details of their pacing. ${ }^{6}$

Meanwhile, the high-definition quality of IMAX $70 \mathrm{~mm}$ film and the fact that there were no wide-angle lenses for IMAX cameras complicated the standard miniature techniques, where filmmakers manipulate depth of field to exaggerate space and depth. They addressed some of these concerns by using larger models, but these presented more challenges in turn, as their higher level of detail, which "everyone agreed was necessary 
for large-format, actually worked against the realism of the shot," to the extent that they ended up dusting the models with powder to reduce their sharpness. ${ }^{7}$ Burtt explains that

So much of special effects is Impressionism [...] but creating impressions for such a huge screen is much harder. Our images were subject to such magnification and sharpness that we feared audiences would suddenly become aware of the imperfections. The medium asks us to see thingseven special effects—-for what they really are, and that's tough. ${ }^{8}$

Indeed, one of the reasons that IMAX has been difficult to use for fiction filmmaking is that it picks up levels of detail that would pass notice in $35 \mathrm{~mm}$.

This tension between generating photorealistic illusion and educating the viewer about the mechanics of said illusions speaks to a larger dynamic in special-effects cinema. As Bukatman explains, by "emphasizing cinema's visuality, special effects foreground principles of perception, while their reflexive, presentational quality emphasizes the technologies of their production." In the context of Special Effects, the specific properties of both IMAX film and new digital-effects systems raised questions about shifts in perception and aesthetics by using material that was well-known to the audience but also designed to highlight shifts in standards of photorealism. Susanne Simpson, producer and writer of the documentary, explains how

Movie illusions are becoming increasingly harder to spot for what they are. Digital technology allows us the ability to manipulate images and to recreate almost everything in this world. In the future people will have to be very visually sophisticated to be able to tell what's real and what isn't. ${ }^{10}$

Simpson's call for media literacy is intended to promote the film's educational qualities to the museum market, but it also suggests that, while the documentary draws upon its audiences' nostalgic attachments to Star Wars

7 Magid, "Amazing Special Effects," 35.

8 Magid, "Amazing Special Effects," 31.

9 Bukatman, “Zooming Out," 254.

10 "NOVA Goes Hollywood: An Interview with Susanne Simpson, Producer of Special Effects," Special Effects Press Kit, Boston: NOVA/WGBH, 1996. 
by valorizing technologies of the past, it also equips its viewers to appreciate, and even question, the digital transformations of the special edition. ${ }^{11}$

\section{Attack of the Clones}

In 2002, IMAX introduced DMR, a process for digitally remastering $35 \mathrm{~mm}$ films for exhibition in the IMAX format. DMR technicians scan the $35 \mathrm{~mm}$ print, use proprietary software to analyze the image's grain, and extrapolate from it, allowing the image to be blown up to IMAX proportions. The soundtrack is also remastered for the IMAX six-channel system. The first DMR release was Ron Howard's Apollo 13, a film chosen for the historical and scientific themes that made it attractive to the museums that housed the majority of IMAX facilities. The second film to undergo the process was Attack of the Clones, whose IMAX version was released six months after it first appeared in cinemas. One reason for the delay was that DMR was a time-consuming and labor-intensive process, but the waiting period also had a significant impact on how audiences experienced the film.

The temporal delay meant that Star Wars fans would have already seen Attack of the Clones, often multiple times, before seeing the IMAX version. Not only did Attack of the Clones have the ubiquity of any Star Wars release, but the promotional campaign had placed a great deal of emphasis on format, as it was the first Star Wars film to be shot entirely with digital cameras (The Phantom Menace used both $35 \mathrm{~mm}$ and HDCAM) and it was shown, with much fanfare, in digital projection. As Richard Grusin explains, Attack of the Clones's digital properties were "heralded in the popular media as marking a watershed moment in the history of film" and were even referenced in the industry as anticipating the end of analog filmmaking. ${ }^{12}$ While many filmgoers would have seen the film in $35 \mathrm{~mm}$ prints, most would also have been acutely aware of its status as a digital text. Given that the audience for the IMAX version would consist of Star Wars fans, who are often highly conscious of even the smallest distinctions among releases and formats, the IMAX version encouraged viewers to contemplate

11 It is worth noting that given IMAX documentaries' long-running engagements and staggered release schedules, Special Effects screened in many markets during the theatrical releases of the special-edition films.

12 Richard Grusin, "DVDs, Video Games, and the Cinema of Interactions," in Post-Cinema: Theorizing 21st Century Film, eds. Shane Denson and Julia Leyda (Falmer: REFRAME Books, 2016), 65 . 
how the film's narrative and aesthetic properties, as well as the theatrical experience, were affected by technological change.

Attack of the Clones is an interesting artifact of IMAX's early DMR period, in that the reformatting reveals the interactions among technologies. First, they decided to change the aspect ratio, accomplished through a combination of reframing and digital pans, to accommodate a shift from the original 2.35:1 to 1.81:1, which would make better use of the vertical immensity of the IMAX screen. They also edited the film for length. IMAX films' duration had been limited to about 40 minutes due to the size of the projector's platter, but DMR productions required much longer run times. Engineers soon realized that a print over two hours in length was simply too heavy for the rotors to handle, so Attack of the Clones had to cut 22 minutes of footage, resulting in significant shifts in narrative, tone, and characterization. ${ }^{13}$ Many of the edits minimized expository dialogue, including several scenes with Jar Jar Binks, Obi-Wan's discussion with Jocasta Nu in the Jedi Temple Archives, C-3PO's introduction of Owen and Beru, and Padmé and Anakin's conversation with Queen Jamillia. They also removed or shortened several of the more light-hearted scenes between Anakin and Padmé, including the awkward exchange upon their reintroduction early in the film and the scene in which they frolic in a field on Naboo. Many regarded the edits as an improvement, helping to resolve inconsistencies in characterization and narrative logic, particularly in the Anakin/Padmé dynamics, where the IMAX version of their relationship has a consistently darker tone that foreshadows its anticipated tragic outcome.

Viewers debated the merits of the changes, but many agreed that the "IMAX version winds up being decently similar to fan edits that succeeded it." ${ }^{14}$ While fan culture has a long tradition of remixing mainstream texts, fan edits had received considerable attention since the release of The Phantom Menace; revisions such as The Phantom Edit began to be distributed among fan networks. ${ }^{15}$ While it is plausible that many Attack of the Clones fan edits were influenced by the IMAX version, it is interesting to think about the

13 Online fan communities made a point of documenting the changes. For example, see "The Definitive IMAX Cut Scenes List," TheForce.net, October 31, 2002, accessed May 15, 2017, http:// www.theforce.net/latestnews/story/the_definitive_imax_cut_scenes_list_64801.asp. 14 Aluminum Falcon, "Star Wars Episode II-Attack of the Clones (2002): IMAX Cut Reconstruction," Fanres, January 11, 2017, accessed May 15, 2017, https://forum.fanres.com/thread-1243. html. Fanres.com is a website devoted to fan restorations of films and television programs. 15 Daniel Kraus, “The Phantom Edit," Salon, November 5, 2001, accessed May 15, 2017, http:// www.salon.com/2001/11/05/phantom_edit/. 
DMR transformation as part of a larger phenomenon of Star Wars films' transmedia reconfigurations.

While changes to the narrative had the closest connection to fan remixing of the story, the shift in scale also encouraged a different kind of engagement with the film, one in which viewers were acutely aware of the possibilities and limits of digital cinema. Since the DMR software was designed to analyze film grain, the fact that the images were shot on HDCAM resulted in some digital artifacts such as pixelation, particularly of textures like hair and fabric. At the same time, the large image allowed viewers to better appreciate the film's astonishing efforts at world-building, with digital mise-en-scène generating compositions so complex that they invite multiple viewings. Kristen Whissel has discussed this moment in special-effects history when animators began to cultivate "digital multitudes," noting how elaborate crowd scenes demonstrated the possibilities of digital effects to create minute detail and vast diegetic spaces. ${ }^{16}$ When screened in IMAX, and especially to viewers who had previously seen Attack of the Clones in smaller formats, the film invites its viewers to look around the image and appreciate these details, while also noting how the unique geometry of the IMAX theatre maximizes the film's dramas of scale. For example, a post on TheForce.net relays the observations of an IMAX projectionist, who notes that:

this movie is much more intimate-you are allowed now to be drawn into the details, of which there are so many that George put in that it's hard to believe! For example, [in a scene on Tatooine] you can see Jawas moving around inside the crawler now [...] The background details become functional instead of just being background-he says you'll probably spend more time watching them than anything else, because we've never been able to see them this clearly before! ${ }^{17}$

Viewers also remarked that action and dialogue scenes alike benefitted from the larger screen. For example, the chase sequence on Coruscant became all the more thrilling thanks to IMAX's capacity to create feelings

16 In her essay, Whissel discusses the appearance of the vast Clone Army on Kamino in Attack of the Clones as an example of such digital multitudes, noting the common visual connection of multitudes with large spaces. Kristen Whissel, "The Digital Multitude," Cinema Journal 49, no. 4 (2010): 97.

17 "AOTC IMAX Cuts and Deletions," TheForce.net, October 30, 2002, accessed May 15, 2017, http://www.theforce.net/latestnews/story/AOTC_IMAX_Cuts_and_Deletions_64824.asp. 
of vertigo, while the immensity of close-ups allowed one to appreciate nuances of actor performances, further enhancing the sense of intimacy.

Each of these observations depends on a combination of factors, including viewers' previous viewings of the film - therefore enabling viewers to take the time to notice changes - and the distinct technologies of IMAX cinemas. It is important to recall that there were very few commercial IMAX venues in 2002, so the experience of seeing a Star Wars movie in a museum or educational institution differentiated it from conventional film spectatorship. With this in mind, it is interesting to note that the poster for Attack of the Clones: The IMAX Experience features Yoda wielding his lightsaber below the tagline "Size Matters Not. Except on An IMAX Screen." While most Star Wars posters show characters against a starfield, Yoda here stands above a map of the United States featuring American landmarks, including Seattle's Space Needle, San Francisco's Golden Gate Bridge, New York's Empire State Building and Statue of Liberty, Dallas's Reunion Tower, St. Louis's Gateway Arch, and Washington D.C.'s Capitol-all cities that house IMAX theatres. The poster playfully references Yoda's commentary on scale from The Empire Strikes Back, but, equally importantly, it identifies this version of the film as a site-specific experience. In the hyper-cinematic spaces of IMAX theatres, viewers were able to access properties of a film that was arguably ahead of its time, with its complex digital multitudes only becoming fully visible on the big screen. Further, if we regard the changes in both narrative and aspect ratio within the larger constellation of Attack of the Clones's transmedia manifestations, from novelizations to fan edits, then the IMAX version stands as a valorization of the creative possibilities of Star Wars's continual remixing and recirculation.

\section{The Force Awakens}

In the thirteen years between the releases of Attack of the Clones and The Force Awakens, IMAX underwent substantial transformations in its exhibition infrastructure and its relationship to mainstream filmmaking. There was a significant expansion of the commercial theatre network and the DMR process was refined and streamlined, such that Hollywood productions now routinely have IMAX releases, sometimes featuring footage shot on IMAX film. Fans of the format were often disappointed with these new cinemas, which tended to have smaller screens and lower-resolution 
digital projection, decrying them as "fake" or "LieMax."18 In contrast, the more traditional GT and Dome facilities - particularly those that retained their $15 / 70$ projection systems - came to represent notions of authenticity and principled cinephilia, in no small part thanks to filmmakers like Christopher Nolan, who makes a point of eschewing digital cameras and valorizing the IMAX $15 / 70$ versions of his films as the most authentic to his vision. ${ }^{19}$ By 2015 , IMAX 15/70 had become a reference point for the value of film in a digital age and it is in this context that The Force Awakens articulated its own production and spectatorship narrative, incorporating IMAX cameras and theaters as part of its rhetoric of nostalgia.

To be clear, the perceived clear divide between analog and digital filmmaking, or the notion of one being more "real" than the other, is based on specious and arbitrary distinctions. The Force Awakens used all manner of digital effects, and was released in every digital format available, including Digital 2D, Digital 3D, IMAX 3 D (Digital), and the motion-seat D-Box system. And yet, advertising for The Force Awakens was careful to emphasize the use of $35 \mathrm{~mm}$ and IMAX film cameras, as well as practical effects such as models, miniatures, and other non-digital techniques, and to ensure that audiences were aware of the option of seeing IMAX film prints. For example, a behind-the-scenes video prepared for the 2015 San Diego Comic-Con emphasizes the similarities between The Force Awakens and the original trilogy on the basis of a pre-digital materiality. ${ }^{20}$

The video is narrated by Mark Hamill and begins with a series of rackfocus shots, each starting with a clapboard, then suddenly shifting focus to reveal evocative sets and props, such as the Millennium Falcon, R2-D2, and stormtrooper helmets. These are followed by images of conceptual paintings, models, and puppets, whereupon Hamill's commentary explains, "Real sets, practical effects: you've been here, but you don't know this story. Nothing's changed, really. I mean, everything's changed, but nothing's changed." Over shots of studio sets, Lupita Nyong'o wearing her motion-capture rig, and Anthony Daniels in costume as $\mathrm{C}-3 \mathrm{Po}$, Hamill's voice continues “To see

18 The best-known objection to smaller IMAX facilities is: Aziz Ansari, "REBLOG THE FUCK OUT OF THIS," Aziz Ansari, May 12, 2009, accessed May 15, 2017, http://azizisbored.tumblr.com/ post/106587114.

19 For further explication of Nolan's use of IMAX, see Allison Whitney, "Cinephilia Writ Large: IMAX in Christopher Nolan's The Dark Knight and The Dark Knight Rises," in The Cinema of Christopher Nolan: Imagining the Impossible, eds. Jacqueline Furby and Stuart Joy (New York: Columbia University Press, 2015), 31-43.

20 "Star Wars: The Force Awakens_-Comic-Con 2015 Reel," StarWars.com, 2015, accessed February 12, 2017, http://www.starwars.com/video/star-wars-the-force-awakens-comic-con-2015-reel. 
how the technology has evolved, and yet, keeping one foot in the pre-digital world" - that final phrase over an image of a film camera, opened so we can see and hear the film running through its gears. Several more film cameras appear throughout the video, including an IMAX rig mounted on the cockpit of the Millennium Falcon.

This video cultivates excitement about the upcoming film in large part by making the case that it will adhere to filmmaking techniques whose roots are in the 1970s, framing viewers' nostalgia in explicitly technological terms. Indeed, the rack focus technique is one of several formal strategies, along with lens flares and handheld cameras, that became popular in the 1970 s as a means of drawing attention to the apparatus of filmmaking. Julie Turnock has argued that these strategies, and their photographic artifacts, have been cultivated for decades in the special effects traditions of Industrial Light and Magic as a means of communicating notions of realism and authenticity. ${ }^{21}$ In contemporary cinema they are often used as a counterpoint to the perceived artificiality of CGI, and J.J. Abrams has come to use lens flares with such regularity that they are something of an authorial signature, even to the point of becoming a joke among fans.

Given the promotional campaign's clear alignment of film with Star Wars's emotional essence, we might read The Force Awakens's IMAX sequence as a spectacle framed by technological nostalgia. Audiences who saw the film in IMAX theatres (whether $15 / 70$ or Digital) would be able to discern the native-IMAX footage because of a change in aspect ratio. As the sequence begins, Rey and Finn run toward a quad-jumper to escape the First Order, and Finn points off-screen to another ship, which Rey dismisses as "garbage." When their intended ship is destroyed, she announces "the garbage will do" and the camera turns to reveal the Millennium Falcon - the first beloved icon from the original trilogy to appear in The Force Awakens. ${ }^{22}$ As they run inside the ship, its presentation in IMAX forces the viewer to contemplate this emotionally loaded space in new terms. Indeed, the higher resolution of IMAX film and the difference in aspect ratio encourage the kind of attention to detail that audiences had experienced with the IMAX version of Attack of the Clones - one feels invited to look around "inside" the Falcon in a way that its earlier representations did not.

21 Julie Turnock, "The ILM Version: Recent Digital Effects and the Aesthetics of 1970s Cinematography," Film History 24, no. 2 (2012): 162.

22 By this point in the film, we have seen familiar technologies, such as the crashed Star Destroyer, and the ruined AT-AT where Rey has built her house. Unlike the Falcon, however, these are more generic relics of the Empire. 
The combination of familiarity and novelty that is integral to the Star Wars experience comes across in a sequence that quite literally brings life to old machines: not only the Falcon, but also the pre-digital film camera that reanimates it. Rey and Finn are not only under siege from the First Order, but they must also contend with the Falcon's antiquated equipment: Rey barely gets the ship off the ground and Finn struggles to operate its ill-maintained weapons. Rey chooses the unlikely but visually thrilling strategy of flying the Falcon inside a ruined Star Destroyer, a spacecraft whose form has become a kind of shorthand in Star Wars iconography for the cinema's capacity to enact dramas of scale, to transform the function of the frame, and to offer ever more moving spectacles. The IMAX sequence uses the combined powers of 15/70 film, practical effects, and cutting-edge digital tools to activate viewers' nostalgia for the cinema of the past; then, this dynamic is mapped onto a spectacle in which the characters resurrect discarded machines, revisit the archaeological ruins of bygone wars, and ultimately unite their respective hero's quests.

While SpecialEffects, Attack of the Clones, and The Force Awakens employ IMAX technology in distinct ways, they each reward audiences' familiarity with Star Wars as a story, an iconographic system, and a cultural phenomenon, as well as encourage audiences to contemplate how different media formats inform the franchise's transmedia manifestations. IMAX iterations of Star Wars use the format's extreme properties of scale, sensory engagement, and image quality to immerse the viewer in the films' visceral and emotional pleasures, while also drawing their attention to the interplay of technology, nostalgia, and collective experience that sustains Star Wars as a cultural force. 